\title{
Human heterochromatin protein 1 isoform HP1 $\beta$ enhances androgen receptor activity and is implicated in prostate cancer growth
}

\author{
M Shiota*, Y Song ${ }^{*}$ A Yokomizo, Y Tada, K Kuroiwa, M Eto ${ }^{1}$, Y Oda ${ }^{2}$, \\ J Inokuchi, T Uchiumi ${ }^{3}$, N Fujimoto $^{4}, N$ Seki and S Naito
}

\begin{abstract}
Department of Urology, Graduate School of Medical Sciences, Kyushu University, 3-1-1 Maidashi, Higashi-ku, Fukuoka 812-8582, Japan

${ }^{1}$ Department of Urology, Graduate School of Medicine, Kumamoto University, Kumamoto 860-8556, Japan

${ }^{2}$ Department of Anatomic Pathology and ${ }^{3}$ Department of Clinical Chemistry and Laboratory Medicine, Graduate School of Medical Sciences, Kyushu University, Fukuoka 812-8582, Japan

${ }^{4}$ Department of Urology, School of Medicine, University of Occupational and Environmental Health, Kitakyushu 807-8555, Japan

(Correspondence should be addressed to A Yokomizo; Email: yokoa@uro.med.kyushu-u.ac.jp)
\end{abstract}

*(M Shiota and $Y$ Song contributed equally to this work)

\begin{abstract}
There are currently few successful therapies for castration-resistant prostate cancer (CRPC). CRPC is thought to result from augmented activation of the androgen/androgen receptor (AR) signaling pathway, which could be enhanced by AR cofactors. In this study, heterochromatin protein $1 \beta(\mathrm{HP} 1 \beta)$, but not HP1 $\alpha$ or HP1 $\gamma$ was found to be an AR cofactor. HP1 $\beta$ interacted with the $A R$, and enhanced the DNA-binding ability of $A R$ to androgen-responsive element in the prostate-specific antigen enhancer and promoter regions, and to increase the transcription of $A R$ target genes. In prostate cancer (PCa) tissues, HP1 $\beta$ expressions correlated with Gleason score and tri-methylation levels of histone $\mathrm{H} 3$ lysine 9. Silencing of HP1 $1 \beta$ suppressed the growth of AR-expressing PCa cells by inducing cell-cycle arrest at the $G_{1}$ phase, similar to inhibition of androgen/AR signaling. Furthermore, HP1 $\beta$ was overexpressed in castration-resistant LNCaP derivative CxR cells, and HP1 $\beta$ knockdown also suppressed the cell growth in CxR cells. These findings indicate that HP1 $\beta$ is involved in the proliferation of AR-expressing PCa cells and progression to CRPC as an AR coactivator. Modulation of HP1 $\beta$ expression or function might be a useful strategy for developing novel therapeutics for PCa, even in CRPC.
\end{abstract}

Endocrine-Related Cancer (2010) 17 455-467

\section{Introduction}

Prostate cancer (PCa) is the most common non-cutaneous cancer and is the second leading cause of cancer-related death in men in developed countries. The incidence of PCa is increasing significantly due to the prevalence of the western-style diet and an increase in the aging population (Hsing \& Devesa 2001, Gronberg 2003). Prostate-specific antigen (PSA) screening has improved the early detection of PCa. However, a quarter of early-stage PCa patients still suffer from the relapse of the disease, despite surgery or radiation therapy (Feldman \& Feldman 2001,
Han et al. 2001, Isaacs et al. 2002). In addition, many patients with $\mathrm{PCa}$ are only diagnosed at an advanced stage of the disease. Androgen-deprivation therapy (ADT) has become the standard therapy, and is practically the only effective treatment for recurrent or advanced PCa. Although most PCas are originally androgen dependent, they eventually become castration resistant during ADT, which is called castrationresistant PCa (CRPC; Debes \& Tindall 2002). There are currently very few successful therapies for CRPC. Therefore, the progression to CRPC represents a very serious problem. In addition, whereas ADT reduces 
cancer-related symptoms, its effectiveness is limited regarding to the improvement of life expectancy of PCa patients. Preventing the progression to CRPC and developing novel effective therapeutics for CRPC would offer hope to many patients with $\mathrm{PCa}$ needing ADT and to those with CRPC.

Androgen receptor (AR) is a ligand-dependent transcription factor and a member of the class I subgroup of the nuclear receptor superfamily. The androgen/AR signaling pathway is thought to play a central role in the development and progression of PCa. AR signaling could be modulated by AR cofactors such as heat-shock protein 27 (Hsp27; Zoubeidi et al. 2007), peroxiredoxin 1 (Park et al. 2007), Tip60 (Shiota et al. 2010c), ARA54 (Miyamoto et al. 2002), ARA55 (Fujimoto et al. 1999) and peroxisome proliferator-activated receptor $\gamma$ coactivator-1 $\alpha$ (Shiota et al. 2010b), a part of which has also been implicated in CRPC. Although changes in the levels of these growth factors and cofactors might stimulate androgen-dependent $\mathrm{PCa}$ to switch to castration-resistant cancer, the mechanism of progression to CRPC remains unknown.

Mammalian heterochromatin protein 1 (HP1), which contains a characteristic chromodomain, plays a critical role in establishing and maintaining heterochromatic domains, which are thought to be transcriptionally inactive (Wang et al. 2000). Three mammalian HP1-like proteins have been identified in humans and are known as HP1 $\alpha$, HP1 $1 \beta$, and HP1 $\gamma$. Each of these contains a chromodomain and a chromoshadow domain that are separated by a hinge region (HR; Lorentz et al. 1994, Eissenberg \& Elgin 2000, Wang et al. 2000). HP1 isoforms exhibit different subnuclear localizations in interphasic nuclei: HP $1 \alpha$ is mainly centromeric; HP $1 \beta$ is also centromeric, but to a lesser extent; and HP1 $\gamma$ is located in both the euchromatic and heterochromatic compartments (Dialynas et al. 2007). HP1 heteromers have been shown to be associated with nucleosomal core histones (Zhao et al. 2000) and reduce the transcription of nearby promoters when tethered to DNA (Cryderman et al. 1999). Furthermore, HP1 proteins in mice and humans interact directly with the transcriptional co-repressor TIF $\beta$, supporting a hypothesis that HP1 proteins play a role in gene silencing (Nielsen et al. 1999). It was shown that methylation of histone H3 lysine 9, which consists of three methylation status (mono-, di-, and tri-methylated histone $\mathrm{H} 3$ lysine 9, referred to as me1H3K9, me2H3K9, and me3H3K9 respectively), creates a binding site for HP1 proteins, and that this modification was involved in the maintenance of permanent heterochromatic loci (Noma et al. 2001, Cheutin et al. 2003). Recently, HP1 $\alpha$ and HP1 $\beta$, but not HP1 $\gamma$, were shown to interact with the tissue-specific transcription factor $\mathrm{MyoD}$, and repressed its transcriptional activity and muscle terminal differentiation (Yahi et al. 2008). In several cancers, HP1 $\alpha$ expression was reported to be decreased compared with the corresponding normal tissues (Pomeroy et al. 2002, Wasenius et al. 2003). On the other hand, it was shown that all HP1 isoforms and meH3K9 were detected in the granulocytes of acute myeloid leukemia and chronic myeloid leukemia, although not detected in those without leukemia (Lukasova et al. 2005).

However, the functions of HP1 protein, both in relation to $\mathrm{AR}$ and in the progression of $\mathrm{PCa}$, remain unknown. In addition, the status of HP1-associated meH3K9 is also unclear in PCa. Therefore, in this study, our aim was to determine the functions of HP1 protein and HP1-associated meH3K9 in association with AR and PCa.

\section{Materials and methods}

\section{Cell culture}

Human normal prostate epithelial RWPE-1 cells (Keratinocyte Serum-Free Medium), human PCa PC-3 (Eagle's Minimal Essential Medium, MEM), DU145 (DMEM), VCaP (DMEM), 22Rv1 (RPMI1640), and LNCaP cells (RPMI1640) were cultured with the indicated media in parentheses, which were purchased from Invitrogen and contained 10\% fetal bovine serum. LNCaP cells propagated between 10 and 30 times were used. Castration-resistant derivatives of LNCaP cells, LNCaP-CxR cells (referred to as CxR cells) were established and maintained as described previously (Shiota et al. 2010a). The cell lines were maintained in a $5 \% \mathrm{CO}_{2}$ atmosphere at $37^{\circ} \mathrm{C}$.

\section{Antibodies}

Antibodies against AR (sc-815), PSA (sc-7316), GFP (sc-8334), and agarose-conjugated anti-GFP antibody (sc-8334 AC) were purchased from Santa Cruz Biotechnology (Santa Cruz, CA, USA). Anti-HP1 $\beta$ (ab49938), anti-histone H3 (ab1791), anti-me1H3K9 (ab9045), anti-me2H3K9 (ab1220), and anti-me3H3K9 (ab8898) antibodies were purchased from Abcam (Cambridge, MA, USA). Anti- $\beta$-actin and anti-HA antibodies were purchased from Sigma and Roche Applied Science respectively. 


\section{Plasmid construction}

The preparation of pCMV-AR and AR-GFP expression plasmid, MMTV reporter plasmid (MMTV-Luc), and PSA reporter plasmid (pGLPSAp5.8) was described previously (Shiota et al. 2010b,c). The construction of pGEX-AR expressing GST-AR and its deletion mutants (GST-AR 1-504, GST-AR 504-920, GST-AR 504-721, GST-AR 567-920, GST-AR 723-920, and GST-AR $\Delta 715-844)$ was described previously (Shiota et al. 2010b). To obtain full-length cDNAs for HP1 $\alpha$, HP1 $\beta$, and HP1 $\gamma$, PCR was carried out on cDNA using the following primer pairs: 5'-ATGGGAAAGAAAACCAAGCGGA$3^{\prime}$ and $5^{\prime}$-TTTAGCTCTTTGCTGTTTCTTTCT- $3^{\prime}$ for HP1 $\alpha ; 5^{\prime}$-ATGGGGAAAAAACAAAACAAGA- $3^{\prime}$ and $5^{\prime}$-TTAGTTCTTGTCATCTTTTTTGTC- $3^{\prime}$ for HP1 $\beta$; and $5^{\prime}$-ATGGCCTCCAACAAAACTACAT- $3^{\prime}$ and $5^{\prime}$-TTATTGAGCTTCATCTTCTGGACA- $3^{\prime}$ for HP1 $\gamma$. PCR products were cloned into the pGEM-T easy vector (Promega). To construct pCMVHA-HP1 $\alpha$, pCMV-HA-HP1 $\beta$, and pCMV-HA-HP1 $\gamma$, fragments of HP1 $\alpha, \mathrm{HP} 1 \beta$, and HP1 $\gamma$ cDNAs were ligated into the pCMV-HA vector (Invitrogen) respectively. The pGEX-HP1 $\beta$ plasmid expressing GST-HP1 $\beta$ was constructed by ligating a fragment of HP1 $\beta$ cDNA into the pGEX vector (GE Healthcare Bio-Science, Piscataway, NJ, USA). Its deletion mutant, GST-HP1 $\beta \Delta \mathrm{C}$, was constructed from pGEX-HP1 $\beta$ full-length plasmids by deletion of the XhoI. GST-HP1 $\beta \Delta \mathrm{N}$ was created from the XhoI fragment of HP1 $\beta$ cDNA.

\section{Western blotting}

The preparation of whole-cell extracts and western blotting were performed as previously described (Shiota et al. 2010a,b,c).

\section{Expression of GST fusion proteins in Escherichia coli and GST pulldown assay}

Expression of GST fusion proteins in E. coli and GST pulldown assay were performed as described previously (Shiota et al. 2010b). Briefly, bacteria transformed with expression plasmids were incubated with $1 \mathrm{mM}$ isopropyl- $\beta$-D-thiogalactopyranoside for $2 \mathrm{~h}$ at room temperature, and collected by centrifugation. After sonication (TAITEC Sonicator, Tokyo, Japan) in CelLytic B Cell Lysis Reagent (Sigma), the cell extracts were cleared by centrifugation at $21000 \mathrm{~g}$ for $10 \mathrm{~min}$ at $4{ }^{\circ} \mathrm{C}$, and their DNAs were degraded with DNase. GST, GST-AR, GST-HP1 $\beta$, or their deletion mutants were immobilized on $10 \mu \mathrm{l}$ of glutathione sepharose 4B (GE Healthcare Bio-Science), and were incubated with the indicated DNase-treated soluble cell extracts in buffer $\mathrm{X}$ for $2 \mathrm{~h}$ at $4{ }^{\circ} \mathrm{C}$. The bound samples were washed three times with buffer $\mathrm{X}$ and subjected to western blot analysis with the indicated antibodies. Purified GST, GST-AR, GST-HP1 $\beta$, or their deletion mutants were stained with CBB. After sonication, DNase-untreated sample containing GST and DNase-treated samples containing GST, GST-AR, GST-HP1 $\beta$, or their deletion mutants were applied to $1 \%$ agarose gel and stained with $\mathrm{EtBr}$.

\section{Co-immunoprecipitation assay}

Co-immunoprecipitation assays were performed as previously described (Shiota et al. 2010b). Nuclear extracts were prepared as follows: after cell harvest with PBS and centrifugation at $5000 \mathrm{~g}$ for $5 \mathrm{~min}$, cells were resuspended in buffer A containing ice-cold $10 \mathrm{mM}$ HEPES/KOH (pH 7.9), $10 \mathrm{mM} \mathrm{KCl}, 0.1 \mathrm{mM}$ EDTA, $0.1 \mathrm{mM}$ EGTA, $1 \mathrm{mM}$ dithiothreitol (DTT), and $0.5 \mathrm{mM}$ phenylmethylsulphonyl fluoride (PMSF), and lysed by adding NP-40 to a final concentration of $0.5 \%(\mathrm{v} / \mathrm{v})$, and lysates were centrifuged at $5000 \mathrm{~g}$ for $5 \mathrm{~min}$. The resulting nuclear pellet was resuspended in buffer $\mathrm{C}$ containing ice-cold $20 \mathrm{mM} \mathrm{HEPES/KOH}$ (pH 7.9), 0.4 M NaCl, 1 mM EDTA, 1 mM EGTA, $1 \mathrm{mM}$ DTT, and $1 \mathrm{mM}$ PMSF, and incubated for $15 \mathrm{~min}$ on ice. The lysates were centrifuged at $21000 \mathrm{~g}$ for $10 \mathrm{~min}$ at $4{ }^{\circ} \mathrm{C}$.

\section{Knockdown analysis using siRNAs}

Knockdown analysis using siRNA was performed as described previously (Shiota et al. 2010a,b,c). Briefly, the following double-stranded RNA, 25-bp oligonucleotides were commercially generated (Invitrogen): 5'-AUUUCAUCAGGAACAUGAGCUCUCC- $3^{\prime}$

(sense) and 5'-GGAGAGCUCAUGUUCCUGAUGAAAU- $3^{\prime}$ (antisense) for HP1 $\beta$ siRNA \#1; 5'-UUGACAUUGGCUUCCUUGGCAGGGA- $3^{\prime}$ (sense) and $5^{\prime}$-UCCCUGCCAAGGAAGCCAAUGUCAA- $3^{\prime}$ (antisense) for HP1 $\beta$ siRNA \#2; 5'-UAGAGAGCAAGGCUGCAAAGGAGUC-3' (sense) and 5'-GACUCCUUUGCAGCCUUGCUCUCUA-3' (antisense) for AR siRNA \#1; 5'-CAUAGUGACACCCAGAAGCUUCAUC- $3^{\prime}$ (sense) and $5^{\prime}$-GAUGAAGCUUCUGGGUGUCACUAUG-3' (antisense) for AR siRNA \#2. LNCaP, CxR, and PC-3 cells were transfected with the indicated amounts of siRNA using Lipofectamine 2000 (Invitrogen) according to the manufacturer's protocol. 


\section{Luciferase reporter assay}

Luciferase reporter assays were performed as described previously (Shiota et al. 2010a,b,c).

\section{Chromatin immunoprecipitation assay}

The chromatin immunoprecipitation assay (ChIP) assay was performed as previously described (Shiota et al. 2010b). Nuclear extract preparation was done as described above in 'Co-immunoprecipitation assay'.

\section{Tissues and clinical data}

The subjects were 35 patients, who received radical prostatectomy without chemotherapy and hormonal therapy before surgery and had enough carcinoma areas for the evaluation of immunohistochemistry, at the Kyushu University Hospital, Japan, between 1997 and 2001. All patients underwent surgery for clinically localized PCa determined by pre-operative PSA concentration, digital rectal examination, and prostate needle biopsy. Slides for this study were prepared from the prostate blocks that contained the largest and representative area of the tumor and adjacent normal epithelium.

\section{Immunohistochemistry}

Immunohistochemistry was performed using the streptavidin-biotin-peroxidase method with a Histofine streptavidin-biotin-peroxidase kit (Nichirei, Tokyo, Japan). The primary antibodies used in this study were anti-HP1 $\beta$ antibody (rabbit polyclonal, dilution 1:1200) and anti-me3H3K9 antibody (rabbit polyclonal, dilution 1:400). Sections, $4-\mu \mathrm{m}$ thick, from $10 \%$ formalin-fixed, paraffin-embedded material were deparaffinized in xylene and rehydrated through ethanol. Then, endogenous peroxidase activity was blocked by methanol containing $0.3 \%$ hydrogen peroxidase for $30 \mathrm{~min}$. Antigen retrieval was performed by microwave heating in citrate buffer ( $\mathrm{pH}$ 6.0) for 20 min for anti-me3H3K9 antibody. After exposure to $10 \%$ non-immunized goat serum in PBS for $10 \mathrm{~min}$, the sections were incubated at $4{ }^{\circ} \mathrm{C}$ overnight with primary antibodies. The sections were then incubated with the second antibody for $20 \mathrm{~min}$ at room temperature. The reaction products were visualized by diaminobenzidine tetrahydrochloride as a chromogen. Finally, the sections were counterstained with hematoxylin.

\section{Immunohistochemical analysis}

To assess the HP1 $\beta$ expression and me3H3K9 level, nuclear staining was evaluated. The immunoreactivity of HP1 $\beta$ expression and me $3 \mathrm{H} 3 \mathrm{~K} 9$ level were scored by estimating the percentage of positive tumor cells. The median percentage of HP1 $\beta$ - and me3H3K9positive tumor cells was 42 and $67 \%$. High HP1 $\beta$ expression and me3H3K9 level were defined as more than 42 and $67 \%$ staining of the population of tumor cells respectively.

\section{RNA isolation, RT-PCR, and quantitative real-time PCR}

These procedures were performed as described previously (Shiota et al. 2010a,b,c).

\section{Cell proliferation assay}

Cell proliferation assays were performed as described previously (Shiota et al. 2010a,b,c). Briefly, PCa cells $\left(2.5 \times 10^{4}\right)$ were seeded into 12 -well plates and transfected with the indicated siRNA. The time point of $12 \mathrm{~h}$ after transfection was set as $0 \mathrm{~h}$. The cells were harvested with trypsin and counted daily using a cell counter (Beckman Coulter, Fullerton, CA, USA). The results were normalized by the cell counts at $0 \mathrm{~h}$, and are representative of at least three independent experiments.

\section{Flow cytometry}

Flow cytometry was performed as described previously (Shiota et al. 2010a,b,c).

\section{Statistical analysis}

We used $\chi^{2}$ test for statistical analysis of the correlations between the HP1 $\beta$ expression or me3H3K9 level, and Gleason score. In the present study, tumors were classified as high grade when the Gleason score was 7 or higher and as low grade when the Gleason score was 6 or lower. Pearson's correlation coefficient analysis was applied across the HP1 $\beta$ expression and me3H3K9 level. Relationships between the HP1 $\beta$ expression and various clinicopathological characteristics were analyzed by $\chi^{2}$ test or Fisher's exact test. Mann-Whitney's $U$ test was used for statistical analysis of HP1 $\beta$ binding to PSA promoter between LNCaP and CxR cells. $P$ values $<0.05$ were considered statistically significant.

\section{Results}

\section{HP1 $\beta$, but not HP1 $\alpha$ or HP1 $\gamma$, interacts with AR and augments AR transcriptional ability}

First, whether three HP1 isoforms interacted with AR was investigated using a GST pulldown assay with GST fusion AR and HA-tagged HP1 isoforms. 
As shown in Fig. 1A, HP1 $\beta$, but not HP1 $\alpha$ or HP1 $\gamma$, interacted with GST-AR. To confirm this finding, we performed a co-immunoprecipitation assay with an overexpression method. PC-3 cells not expressing AR protein were transfected with GFP-tagged AR and HA-tagged HP1 isoform expression plasmids, and the co-immunoprecipitation assay was performed. Reproducibly, HP1 $\beta$, but not HP1 $\alpha$ or HP1 $\gamma$, specifically interacted with the AR-GFP protein (Fig. 1B). Finally, we investigated whether endogenous proteins interacted with each other. Using nuclear extracts of $\mathrm{LNCaP}$ cells expressing AR protein, the endogenous AR was immunoprecipitated using anti-AR antibody, and immunoprecipitated samples were blotted with anti-HP1 $\beta$ antibody. As expected, the endogenous AR interacted with the endogenous HP1 $\beta$ in the presence of dihydrotestosterone (DHT), but not in the absence of DHT since AR was excluded from HP1 $\beta$-existing nucleus (Fig. 1C).
Because HP1 $\beta$ interacted with AR, we determined the effect of HP1 $\beta$ on AR transcriptional activity using a luciferase assay. First, LNCaP cells were transfected with the PSA reporter plasmid, pGLPSAp5.8, which contained three putative androgen-responsive elements (AREs) within the PSA enhancer and promoter regions (about $5.8 \mathrm{~kb}$ ) and HP1 isoform expression plasmids. Luciferase activity was hardly detected in the absence of androgen. However, in the presence of androgen, the luciferase activity was significantly increased. In addition, HP1 $\beta$ expression augmented the luciferase activity driven by PSA enhancer and promoter, although control Renilla luciferase activity was not affected (data not shown). Similar results were obtained when we used MMTV-Luc, which is known to be stimulated by AR. Next, luciferase reporter assays were conducted in PC-3 cells transfected with pCMV-AR plasmid, which expresses wild-type AR protein driven by cytomegalovirus promoter and not
A
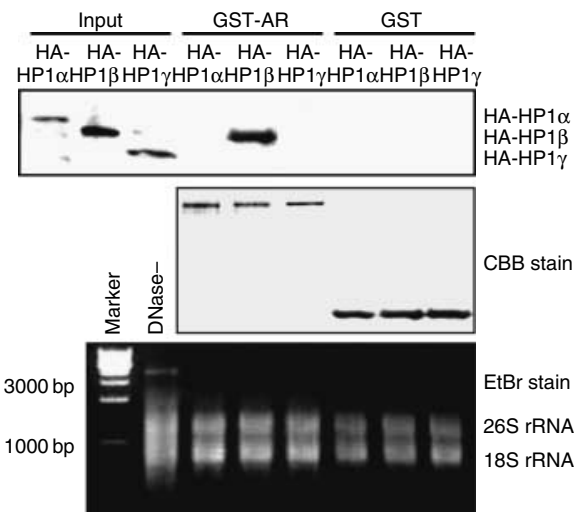

B

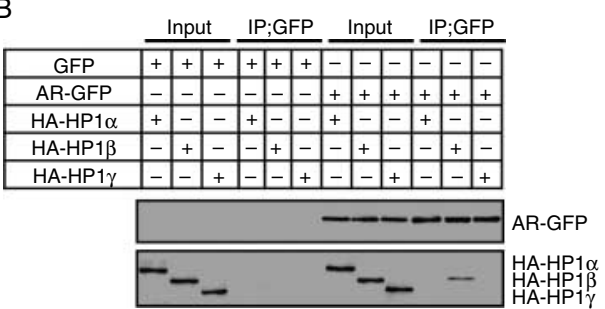

C
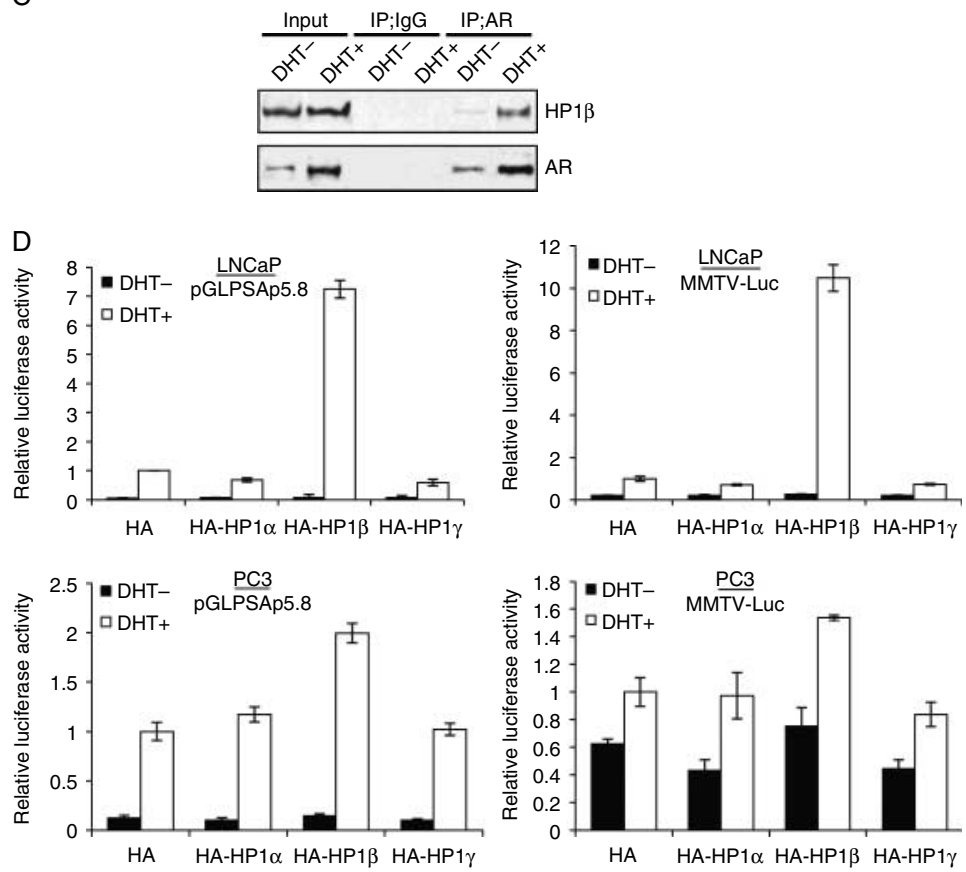

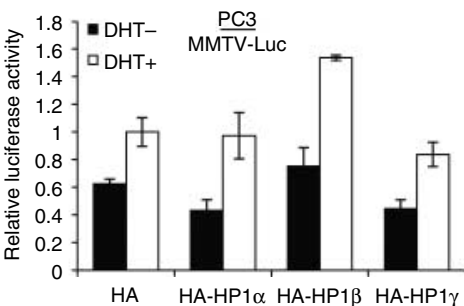

Figure $1 \mathrm{HP} 1 \beta$, but not $\mathrm{HP} 1 \alpha$ or $\mathrm{HP} 1 \gamma$, interacts with AR and augments AR transcriptional activity. (A) Equal amounts of GST and GST-AR fusion proteins immobilized on glutathione sepharose 4B were incubated with HA-HP1 $\alpha, \mathrm{HA}-\mathrm{HP} 1 \beta$, and HA-HP1 $\gamma$ fusion proteins. Bound protein and $10 \%$ of the input were subjected to SDS-PAGE, and western blotting was performed using the anti-HA antibody. (B) Whole-cell extracts prepared from PC-3 cells co-transfected with $1.0 \mu \mathrm{g}$ of each of the indicated expression plasmids were immunoprecipitated with agarose-conjugated anti-GFP antibody. The resulting immunocomplexes and whole-cell extracts were subjected to SDS-PAGE, and western blotting was performed using anti-HA and anti-GFP antibodies. (C) Nuclear extracts prepared from LNCaP cells incubated for $48 \mathrm{~h}$ in charcoal-stripped medium with or without $10 \mathrm{nM}$ DHT were immunoprecipitated with $2.0 \mu \mathrm{g}$ of rabbit IgG or anti-AR antibody, and $20 \mu \mathrm{l}$ of protein A/G agarose. The resulting immunocomplexes and nuclear extracts were subjected to SDS-PAGE, and western blotting was performed using the indicated antibodies. (D) LNCaP and PC-3 cells were transfected with $0.5 \mu \mathrm{g}$ of the indicated reporter plasmids, $0.5 \mu \mathrm{g}$ of the indicated expression plasmids, and $0.05 \mu \mathrm{g}$ of $\mathrm{pRL}-\mathrm{TK}$, in addition to $0.5 \mu \mathrm{g}$ of pCMV-AR when PC-3 cells were used. Then, cells were incubated for $48 \mathrm{~h}$ in charcoal-stripped medium with or without $10 \mathrm{nM}$ DHT. Firefly luciferase activity was corrected with the corresponding Renilla luciferase activity. All values represent at least three independent experiments. The luciferase activity of each reporter plasmid alone incubated in medium with DHT was defined as 1. Boxes, mean; bars, \pm s.D. 
affected by HP1 isoform expression (data not shown). Similarly, luciferase activities of the PSA and MMTV reporter plasmids were enhanced only with HP1 $\beta$ overexpression (Fig. 1D).

\section{The chromoshadow domain of HP1 $\beta$ interacts with the DNA-binding domain and HR of AR}

The findings that HP1 $\beta$ interacted with AR and had a functional role with AR promoted us to examine which domains are involved in this interaction. First, a GST pulldown assay was performed using GST-AR and a series of deletion mutants with HA-tagged HP1 $\beta$ (Fig. 2A). As shown in Fig. 2B, HP1 $\beta$ seemed to interact with the DNA-binding domain (DBD) and HR of AR. Next, GST-HP1 $\beta$ and its deletion mutants with nuclear extracts of $\mathrm{LNCaP}$ were used for the GST pulldown assay (Fig. 2C). As shown in Fig. 2D, the full-length GST-HP1 $\beta$ and N-terminally deletedGST-HP1 $\beta$, but not C-terminally deleted-GST-HP1 $\beta$, interacted with the AR protein, suggesting that the chromoshadow domain of HP1 $\beta$ interacts with AR.

\section{HP1 $\beta$ augments the DNA-binding ability of AR}

The PSA enhancer and promoter regions contain three AREs known as ARE I, ARE II, and ARE III (Fig. 3A). First, we investigated histone $\mathrm{H} 3$, me1H3K9, me $2 \mathrm{H} 3 \mathrm{~K} 9$, me3H3K9, and HP1 $\beta$ bindings to PSA promoter and enhancer regions and GAPDH promoter region as a control. As shown in Fig. 3B, HP1 $\beta$ bindings to PSA promoter regions (PSA A/B and PSA $\mathrm{C} / \mathrm{D})$ were richer compared with PSA enhancer regions (PSA E/F, PSA G/H, and PSA I/J) in LNCaP cells. In addition, the bindings of me1H3K9, me2H3K9, and me3H3K9 were also more abundant in promoter regions (PSA A/B and PSA C/D). Furthermore, HP1 $\beta$ bindings to PSA promoter regions (PSA A/B and PSA $\mathrm{C} / \mathrm{D})$ in $\mathrm{CxR}$ cells were increased compared with those in LNCaP cells. In addition, me1H3K9 and me2H3K9 bindings to PSA enhancer regions (PSA E/F, PSA G/H, and PSA I/J) and me3H3K9 bindings to PSA promoter regions (PSA A/B and PSA C/D) were also more apparent in $\mathrm{CxR}$ than those in $\mathrm{LNCaP}$ cells. Because HP1 $\beta$ was suggested to interact with the DBD and HR of AR, we investigated whether the DNA-binding ability of AR was affected by HP1 $\beta$ manipulation. When samples immunoprecipitated with the anti-AR antibody were amplified using ARE-containing primer pairs, PCR products were detected when the primer pairs $\mathrm{A} / \mathrm{B}, \mathrm{C} / \mathrm{D}$, and $\mathrm{G} / \mathrm{H}$ were used, but not when primer pairs $\mathrm{E} / \mathrm{F}$ and $\mathrm{I} / \mathrm{J}$ were used. In addition, AR bindings to AREs were further increased by adding DHT, as shown
A

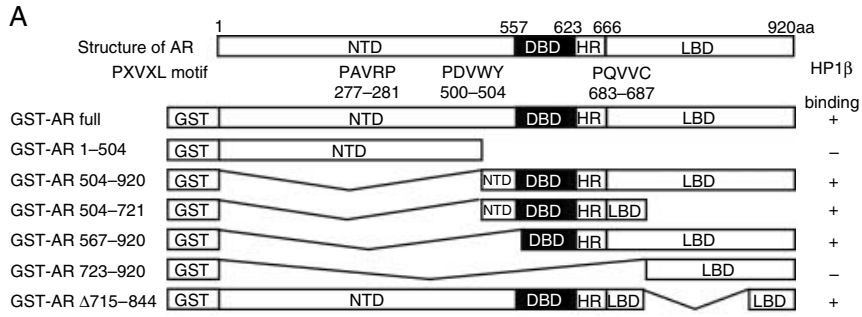

B

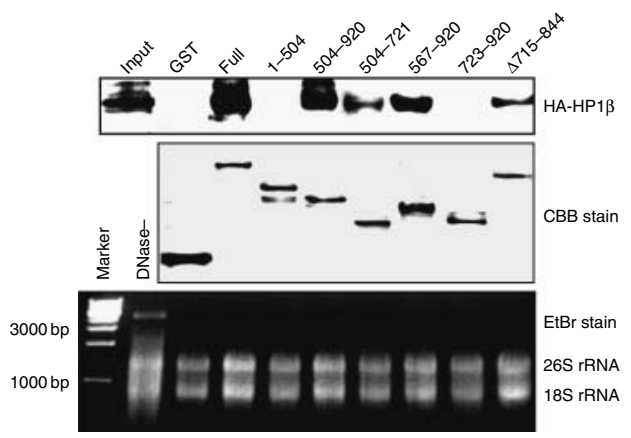

C

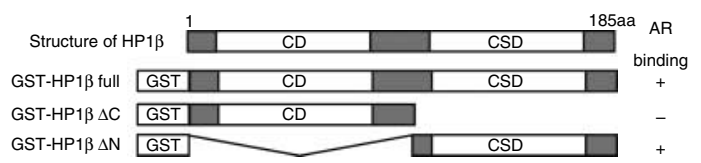

D

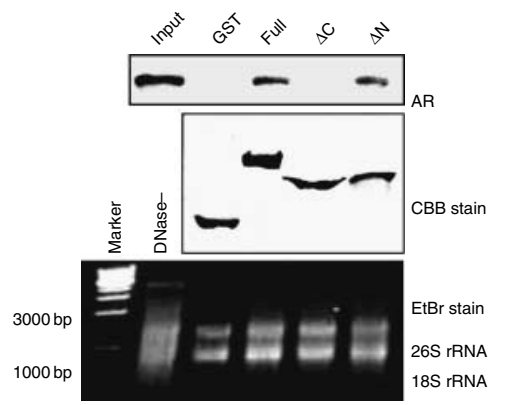

Figure 2 The chromoshadow domain of HP1 $\beta$ interacts with the DNA-binding domain and hinge region of AR. (A) Schematic representation of the GST-AR deletion mutants. (B) Equal amounts of GST, GST-AR, and various GST-AR deletion mutant fusion proteins shown in $(A)$, were immobilized on glutathione-sepharose 4B and were incubated with HA-HP1 $\beta$ fusion protein. Bound protein samples and $10 \%$ of the input were subjected to SDS-PAGE, and western blotting was performed using an anti-HA antibody. (C) Schematic representation of the GST-HP1 $\beta$ deletion mutants. (D) Equal amounts of GST, GST-HP1 $\beta$, and various GST-HP1 $\beta$ deletion mutant fusion proteins shown in (C) were immobilized on glutathione sepharose $4 \mathrm{~B}$, and were incubated with whole-cell lysates from LNCaP cells. Bound protein samples and $10 \%$ of the input were subjected to SDS-PAGE, and western blotting was performed using an anti-AR antibody. 
A

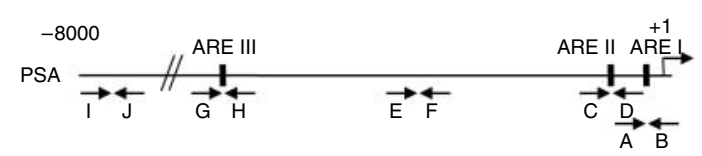

B

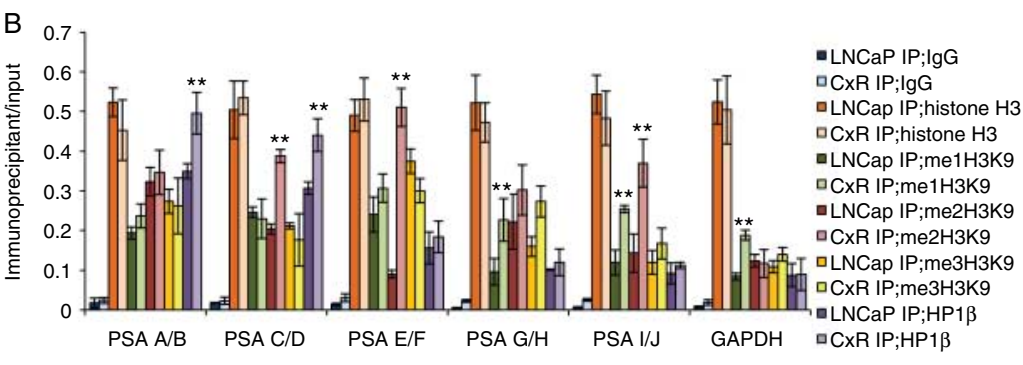

C
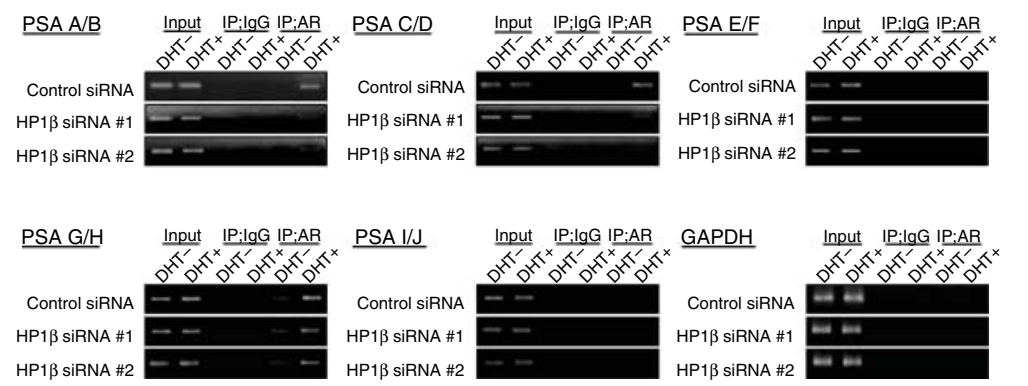

$\mathrm{D}$
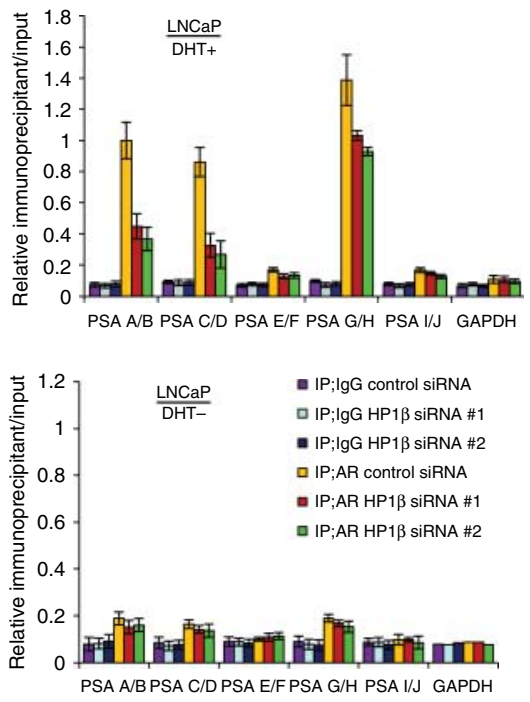

Figure $3 \mathrm{HP} 1 \beta$ augments the DNA-binding ability of AR. (A) Black boxes and black arrows indicate AREs and PCR primer regions respectively. (B) Nuclear extracts from LNCaP cells were immunoprecipitated using $2.0 \mu \mathrm{g}$ of rabbit lgG or the indicated antibodies, and $20 \mu$ of protein $A / G$ agarose. The quantitative real-time PCR was performed using the following primer pairs: PSA A/B, -250 to -39 bp; PSA C/D, -406 to -164 bp; PSA E/F, -1997 to -1846 bp; PSA G/H, -4170 to -3978 bp; PSA I/J, -7694 to $-7484 \mathrm{bp}$; GAPDH, -1455 to $-1365 \mathrm{bp}$. The results of immunoprecipitated samples were corrected for the results of the corresponding soluble chromatin samples. All values represent at least three independent experiments. Boxes, mean; bars, \pm s.D. ${ }^{\star \star} P<0.05$ (compared with binding in LNCaP cells). (C) LNCaP cells were transfected with $40 \mathrm{nM}$ of the indicated siRNA, and were incubated in charcoal-stripped medium with or without $10 \mathrm{nM} \mathrm{DHT}$ for $72 \mathrm{~h}$. Nuclear extracts were immunoprecipitated using $2.0 \mu \mathrm{g}$ of rabbit IgG or anti-AR antibody, and $20 \mu \mathrm{l}$ of protein $\mathrm{A} / \mathrm{G}$ agarose. Soluble chromatin and immunoprecipitated DNAs were amplified by PCR using the primer pairs used in (B). The representative results of three-times ChIP assays are shown. (D) The quantitative real-time PCR was performed using samples and primer pairs used in (C). The results of immunoprecipitated samples were corrected for the results of the corresponding soluble chromatin samples. All values represent at least three independent experiments. Boxes, mean; bars, \pm S.D.

previously (Shang et al. 2002). Furthermore, when HP1 $\beta$ expression was down-regulated by transfecting LNCaP cells with HP1 $\beta$-specific siRNAs, it was found that AR bindings to AREs within the PSA enhancer and promoter regions (PSA A/B, PSA C/D, and PSA G/ $\mathrm{H})$ were reduced (Fig. 3C). These findings were confirmed by quantitative real-time PCR method (Fig. 3D).

\section{Both HP1 $\beta$ expressions and methylated levels of histone $\mathrm{H} 3$ lysine 9 are abundant in $\mathrm{PCa}$ and HP1 $\beta$ expression correlated with Gleason score and me3H3K9 level}

To investigate a relevance of HP1 $\beta$ in $\mathrm{PCa}$, we performed western blotting analysis using normal prostate epithelial cells and a panel of PCa cells. $\mathrm{HP} 1 \beta$ expressions were up-regulated in all $\mathrm{PCa}$ cells compared with normal prostate epithelial cells
(RWPE-1 cells). Furthermore, me1H3K9, me2H3K9, and me3H3K9, which were known to have a relationship with HP1 proteins, were also more prominent in $\mathrm{PCa}$ cells than in RWPE-1 cells (Fig. 4A). Then, we investigated HP1 $\beta$ expression and me3H3K9 level as a representative of meH3K9 forms using PCa tissues. The expression of HP1 $\beta$ was weakly positive in the nuclei of normal prostatic glands. Nuclei of stromal cells of normal prostate parenchyma displayed weak to moderate expression of HP $1 \beta$. The expression of HP1 $\beta$ was weak to moderate and moderate to strong in PCas of Gleason scores 6 and 8 respectively (Fig. 4B).

Me3H3K9 staining was weakly to moderately positive in both the nuclei of normal prostatic glands and the nuclei of stromal cells of normal prostate parenchyma. Nuclear staining of me3H3K9 was moderate to strong in PCa (Fig. 4C). Although HP1 $\beta$ 

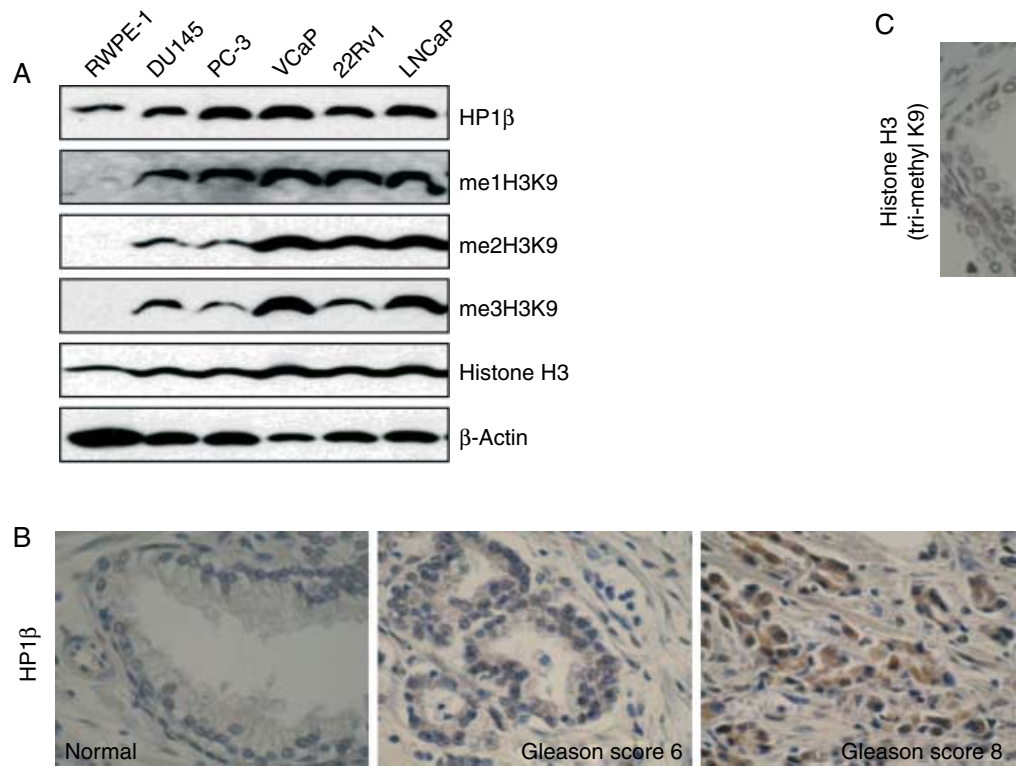

C

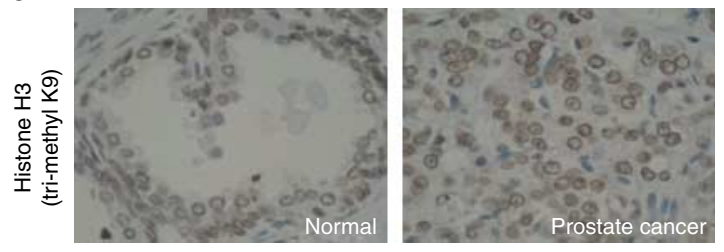

D

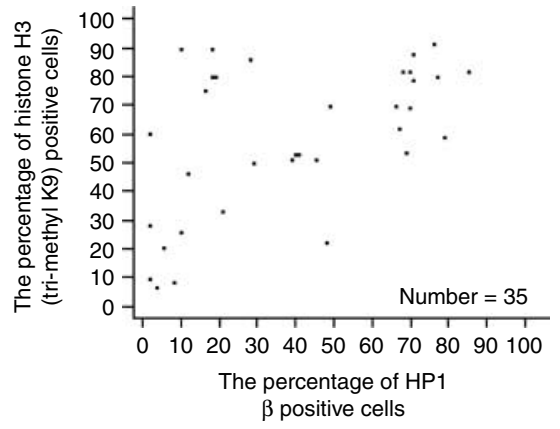

Pearson's correlation coefficient $r=0.5749, P=0.0007$

Figure 4 HP1 $\beta$ expressions and meH3K9 levels are abundant in PCa, and HP1 $\beta$ expression correlates with Gleason score and me3H3K9. (A) Whole-cell extracts of RWPE-1 and a panel of PCa cells were subjected to SDS-PAGE, and western blotting was performed using the indicated antibodies. (B) The representative results of immunohistochemistry of HP1 $\beta$ of normal prostate epithelium and PCas of Gleason scores 6 and 8 are shown. (C) The representative results of immunohistochemistry of me3H3K9 of normal prostate epithelium and $\mathrm{PCa}$ are shown. (D) The staining intensities of HP1 $\beta$ and me3H3K9 correlated with each other.

expression was significantly prominent in PCas of higher Gleason score compared to those of lower Gleason score cancer $(P=0.0266$, Table 1$)$, me3H3K9 staining was not associated with Gleason score $(P=0.4035)$. When individual tumors were analyzed for the nuclear expression of HP1 $\beta$ with nuclear staining of me3H3K9, a correlation was found $(r=0.5749, P=0.0007$; Fig. 4D).

\section{Knockdown of HP1 $\beta$ reduces the PSA expression and cell growth in AR-expressing PCa cells}

To confirm the function of HP1 $\beta$ on the AR, we next examined the expression of PSA after knockdown of HP1 $\beta$. Quantitative real-time PCR and western blotting were performed using $\mathrm{LNCaP}$ cells transfected with HP1 $\beta$-specific siRNAs. Expression of the PSA transcript and protein was decreased by HP1 $\beta$ knockdown. In addition, expression levels of AR transcript and protein also were marginally reduced, cooperatively contributing to a decrease in PSA expression (Fig. 5A). Furthermore, we investigated the cell proliferation of LNCaP cells transfected with HP1 $\beta$-specific siRNAs with androgen-containing medium. Cell proliferation was significantly reduced by knockdown of HP1 $\beta$ (Fig. 5B). Similar results were obtained by AR knockdown (data not shown). To clarify the mechanism by which HP1 $\beta$ knockdown inhibited cell growth, we used flow cytometry for cell-cycle analysis. As shown in Fig. 5C, HP1 $\beta$ knockdown induced cellcycle arrest at the $\mathrm{G}_{1}$ phase similar to AR knockdown

Table 1 Relationship between the expression of heterochromatin protein $1 \beta(\mathrm{HP} 1 \beta)$ and various clinicopathological characteristic

\begin{tabular}{|c|c|c|c|c|}
\hline \multirow[b]{2}{*}{ Variable } & \multirow[b]{2}{*}{$n$} & \multicolumn{2}{|c|}{ HP1 $\beta$ expression } & \multirow[b]{2}{*}{$P$ value } \\
\hline & & Low & High & \\
\hline \multicolumn{5}{|l|}{ Age } \\
\hline$<70$ & 14 & 7 & 7 & \multirow[t]{2}{*}{0.8902} \\
\hline$\geq 70$ & 21 & 10 & 11 & \\
\hline \multicolumn{5}{|l|}{ PSA } \\
\hline$<10$ & 19 & 10 & 9 & \multirow[t]{2}{*}{0.8864} \\
\hline$\geq 10$ & 12 & 6 & 6 & \\
\hline \multicolumn{5}{|c|}{ Gleason score } \\
\hline$<7$ & 16 & 11 & 5 & \multirow[t]{2}{*}{$0.0266^{\mathrm{a}}$} \\
\hline$\geq 7$ & 19 & 6 & 13 & \\
\hline \multicolumn{5}{|l|}{ Stage } \\
\hline pT2 & 26 & 12 & 14 & \multirow[t]{2}{*}{$0.7112^{b}$} \\
\hline рT3-4 & 9 & 5 & 4 & \\
\hline \multicolumn{5}{|c|}{ Surgical margin } \\
\hline Negative & 26 & 12 & 14 & \multirow[t]{2}{*}{$0.7112^{b}$} \\
\hline Positive & 9 & 5 & 4 & \\
\hline
\end{tabular}

aStatistically significant.

${ }^{\mathrm{b}}$ Fisher's extract test. 
A

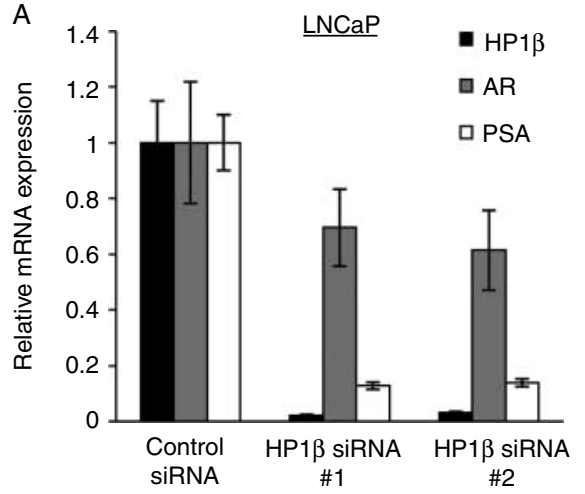

C
$\underline{L \mathrm{NCaP}}$

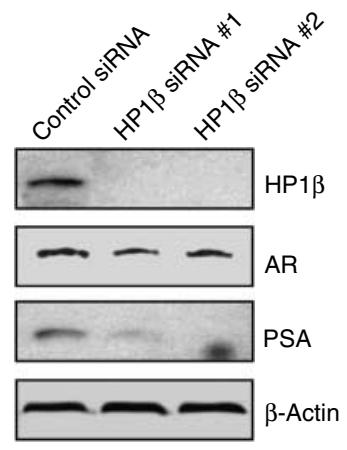

$\underline{\text { LNCaP }}$

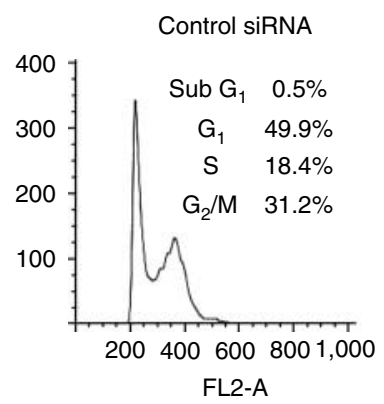

B

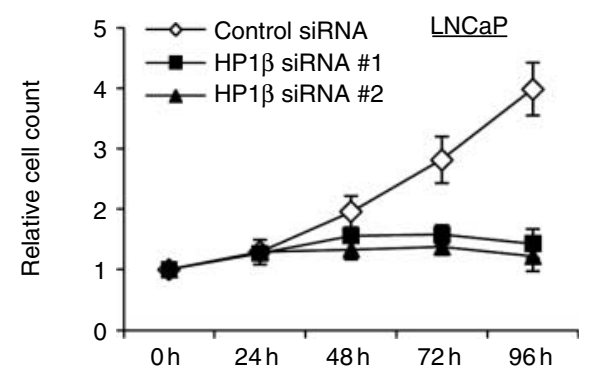

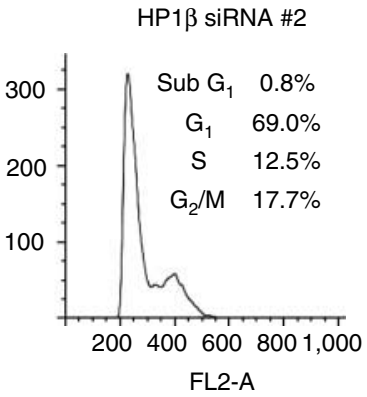

Figure 5 Knockdown of HP1 $\beta$ reduces PSA expression and cell growth in LNCaP cells. (A) LNCaP cells were transfected with $40 \mathrm{nM}$ of the indicated siRNA. At $72 \mathrm{~h}$ post-transfection, quantitative real-time PCR was performed using the indicated primers and probes. The transcript level of the target transcript was corrected with the corresponding GAPDH transcript level. All values represent at least three independent experiments. The level of each transcript from cells transfected with control siRNA was defined as 1. Boxes, mean; bars, \pm S.D. Whole-cell extracts were subjected to SDS-PAGE, and western blotting was performed using the indicated antibodies. (B) LNCaP cells were transfected with $40 \mathrm{nM}$ of the indicated siRNA, and incubated in charcoal-stripped medium with $10 \mathrm{nM}$ DHT. The number of cells was counted at the indicated times. The results were normalized to the number of cells at $0 \mathrm{~h}$. All values represent at least three independent experiments. Boxes, mean; bars, \pm s.D. (C) LNCaP cells were transfected with $40 \mathrm{nM}$ of the indicated siRNA, and incubated in charcoal-stripped medium with $10 \mathrm{nM} \mathrm{DHT}$. At $72 \mathrm{~h}$ post-transfection, cells were stained with propidium iodide and analyzed by flow cytometry. The cell-cycle fraction is shown in the upper right position of each graph.

or androgen depletion (data not shown), resulting in decreased cell proliferation. To confirm the effect of HP1 $\beta$ silencing on its interaction with AR, PC-3 cells not expressing AR protein underwent a cell proliferation assay. HP1 $\beta$ knockdown in PC-3 cells affected cell proliferation to lesser extent compared with that in LNCaP cells (Fig. 6A). Finally, we examined whether $\mathrm{HP} 1 \beta$ is involved in castration-resistant progression. Similarly to LNCaP cells, PSA protein expression was reduced when the castration-resistant $\mathrm{CxR}$ cells were transfected with HP1 $\beta$-specific siRNAs (Fig. 6B). The expressions of HP1 $\beta$ transcript and protein and the levels of meH3K9 were increased in CxR cells compared with that in parental cells, indicating that HP1 $\beta$ expression and meH3K9 modifications may be involved in the development of castration resistance (Fig. 6C). The overexpression of AR or AR coactivators is thought to cause CRPC cell growth even under androgen-depleted conditions by augmenting AR signaling. Because CxR cells show enhanced HP1 $\beta$ expression, inhibition of AR signaling may also inhibit cell proliferation in CxR cells. As expected, HP1 $\beta$ knockdown in CxR cells decreased cell proliferation more effectively than in their parental LNCaP cells probably by blocking AR signaling, which was consistent with the results of AR knockdown (Fig. 6D).

\section{Discussion}

In mammals, HP1 proteins have a propensity to homoor heterodimerize, associate with chromatin through meH3K9, and act as a gene repressor (Eissenberg \& Elgin 2000). However, our results revealed that HP1 $\beta$ specifically interacts with AR and transactivated AR-responsive genes. Recently, it has been shown that HP1 proteins could work at euchromatic regions and work as a gene activator despite their name, localization, and suggested function (Piacentini et al. 2003, Hediger \& Gasser 2006, de Wit et al. 2007, Fanti \& Pimpinelli 2008). In addition, histone 

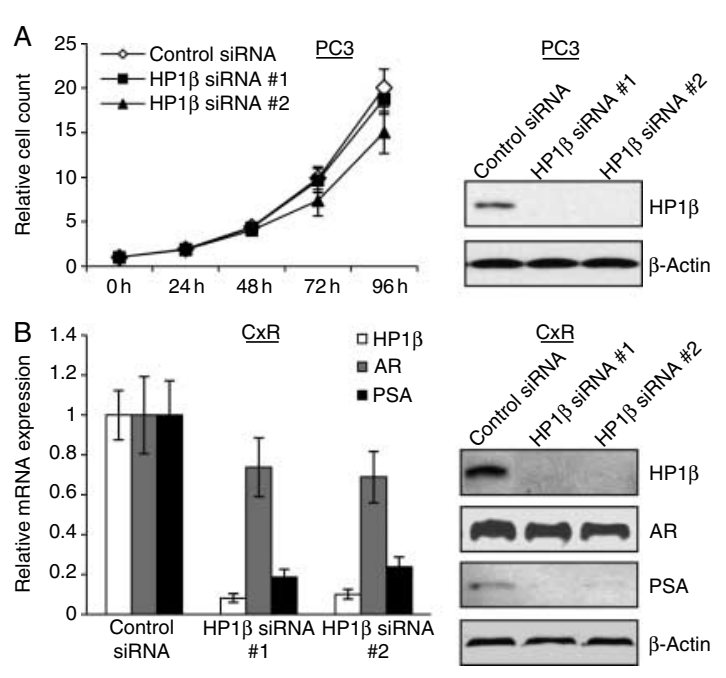
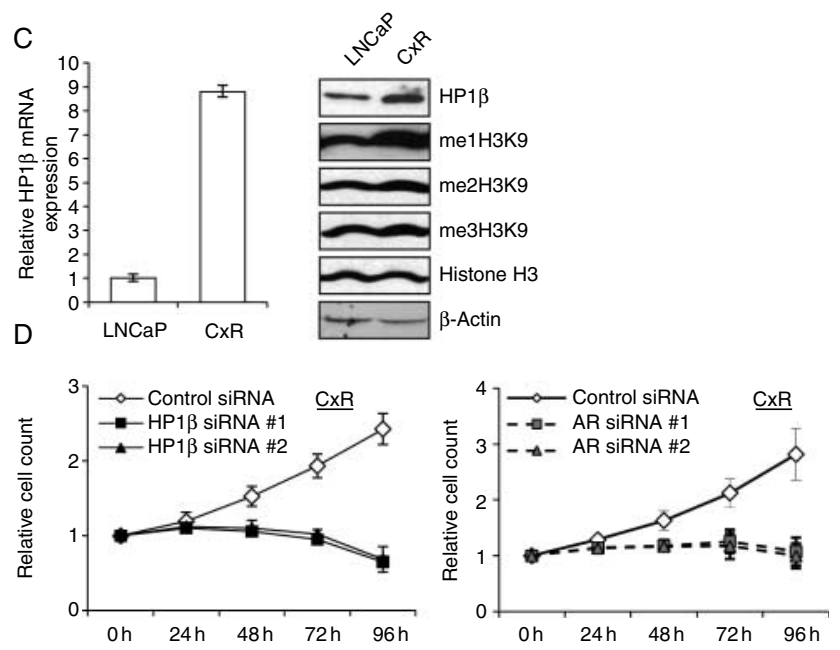

Figure 6 Knockdown of HP1 $\beta$ reduces PSA expression and cell growth in CxR cells, but not in PC-3 cells. (A) PC-3 cells were transfected with $40 \mathrm{nM}$ of the indicated siRNA, and incubated. The number of cells was counted at the indicated times. The results were normalized to the number of cells at $0 \mathrm{~h}$. All values represent at least three independent experiments. Boxes, mean; bars, \pm s.D. Whole-cell extracts were subjected to SDS-PAGE, and western blotting was performed using the indicated antibodies. (B) CxR cells were transfected with $40 \mathrm{nM}$ of the indicated siRNA. At $72 \mathrm{~h}$ post-transfection, quantitative real-time PCR was performed using the indicated primers and probes. The transcript level of the target transcript was corrected with the corresponding GAPDH transcript level. All values represent at least three independent experiments. The level of each transcript from cells transfected with control siRNA was defined as 1 . Boxes, mean; bars, \pm s.D. Whole-cell extracts were subjected to SDS-PAGE, and western blotting was performed using the indicated antibodies. (C) Quantitative real-time PCR was performed using cDNA from LNCaP and CxR cells by the primers and probes for HP1 $\beta$ and GAPDH. The transcript level of the target transcript was corrected with the corresponding GAPDH transcript level. All values represent at least three independent experiments. The HP1 $\beta$ transcript level in LNCaP cells was defined as 1 . Boxes, mean; bars, \pm s.D. Whole-cell extracts prepared from LNCaP and CxR cells were subjected to SDS-PAGE, and western blotting was performed using the indicated antibodies. (D) CxR cells were transfected with $40 \mathrm{nM}$ of the indicated siRNA, and incubated in charcoal-stripped medium without DHT. The cell proliferation assay was performed as described in (A).

methyltransferase, NSD2, was reported to interact with meH3K9 and to stimulate AR transactivation (Kang et al. 2009). Taken together, HP1 $\beta$ can act as a transcription activator coordinately with NSD2, which may promote methylation of histone $\mathrm{H} 3$ lysine 9 and recruit HP1 proteins.

It is known that the chromoshadow domain of HP1 $\beta$ interacts with several proteins. In addition, this study revealed that chromoshadow domain of HP1 $\beta$ interacted with AR. On the other hand, the chromodomain of HP1 $\beta$ is supposed to interact with chromatin which is marked with meH3K9. This prompted us to determine whether HP1 $\beta$ could affect the DNAbinding ability of AR. Therefore, we carried out a ChIP assay, which showed that AR binding to the AREs in which the HP1 $\beta$ and meH3K9 bindings were rich was decreased by HP1 $\beta$ knockdown. This finding should justify the results of our GST pulldown assay, which indicated that HP1 $\beta$ interacts with the 567-721 amino acid region of AR that contains the DBD. HP1 $\beta$ proteins are known to interact with meH3K9. Taken together, HP1 $\beta$ might augment the transcriptional activity of AR by modulating an interaction between the chromatin containing ARE and DBD of AR as a scaffold together with meH3K9. In addition, the effect of HP1 $\beta$ siRNA on AR binding may be indirect, and alterations in chromatin structure may contribute to AR binding to ARE because methylated histones and its associated factors can alter chromatin structure and binding of transcription factors, resulting in alterations of gene expression.

On the other hand, as shown in Table 1, there was no correlation between pre-operative serum PSA levels in $\mathrm{PCa}$ patients and HP1 $\beta$ expression in PCa tissues, which seemed to be inconsistent with the finding that HP1 $\beta$ augmented PSA expression. However, it may be accounted for by the fact that serum PSA level and PSA expression are affected by various factors including prostate volume, prostate inflammation, and aging as well as androgen level and AR activity.

HP1 $\beta$ was found to decrease cell proliferation in ECR-293 cells not expressing AR (data not shown), which are daughter cells of HEK293 cell line, and to sensitize cells to ionizing irradiation (Sharma et al. 2003). In addition, it was shown that $\mathrm{Rb}$ protein interacted with Suv39h1 and HP1, recruiting them to 
E2F promoters to establish repression (Nielsen et al. 2001). On the other hand, our result indicated that HP1 $\beta$ knockdown suppressed the proliferation of AR-positive PCa cells by interacting with AR. These findings seem to disagree with previous findings. Whereas cell lines in which it was shown previously that cell growth was decreased by HP1 $\beta$ do not express AR protein (data not shown), most PCas have a functional AR. Therefore, this inconsistency could be explained by the AR expression status, supported by the finding that PC-3 cells not expressing AR were not affected by HP1 $\beta$ knockdown. Taken together, differences of biological effect in HP1 $\beta$ among various cells may represent a specific role of HP1 $\beta$ associated with AR. Intriguingly, it was reported that in Drosophila, HP1 downregulation by RNA interference resulted in a preferential lethality of male flies, and HP1 bonded onto chromosomes more highly in males than in females and regulated more gene expression in males, suggesting that HP1 plays a sex-specific role (Liu et al. 2005). Consistently, mutations in HP1-associated Su(var)3-7 and $S u(v a r)$ 2-5 genes caused a bloating of the $\mathrm{X}$ chromosome in males (Spierer et al. 2005). Similarly, double knockout male mice of HP1-associated histone methyltransferase Suv39h1 and Suv39h2 were infertile with a delay in meiosis (Peters et al. 2001).

In this study, HP1 $\beta$ expressions and meH3K9 levels were found to correlate with each other in PCa. To our knowledge, this is first report that HP1 $\beta$ expressions correlated with meH3K9 levels in cancer tissues. Although a correlation between HP1 $\beta$ and meH3K9 has been found, the mechanism of control of HP1 $\beta$ expression and meH3K9 level remains unclear. However, this result suggests that an unknown common factor regulates HP1 $\beta$ expression and meH3K9 level. Both HP1 $\beta$ expressions and meH3K9 levels were abundant and correlate with each other in $\mathrm{PCa}$, suggesting that these epigenetic alterations are involved in a carcinogenesis of prostate epithelium. However, HP1 expression was reported to be reduced in several cancers (Pomeroy et al. 2002, Wasenius et al. 2003). Because PCa growth is well known to be regulated by androgen/AR signaling, this inconsistency may be accounted by androgen dependency in PCa. Furthermore, high HP1 $\beta$ expression correlated with high Gleason score, which is known to have a tendency of progression to CRPC. These results indicate that HP1 $\beta$ and epigenetic regulations coordinately promote PCa progression. Recently, AR-regulated gene expression was shown by ChIP on chip assay to shift according to a progression from androgen-dependent PCa to CRPC (Wang et al. 2009). Since several cofactors including HP1 $\beta$ can modulate the DNA-binding ability of AR, some of them may participate in alterations of AR target genes. Furthermore, epigenetic alterations including histone modifications would also be involved in target gene selection of AR since histone modification status altered as shown in Fig. 3B.

In conclusion, the HP1 isoform HP1 $\beta$ specifically interacted with $\mathrm{AR}$ and augmented $\mathrm{AR}$ binding to the promoter region of its target gene and transcriptional regulation of AR. HP1 $\beta$ expression and meH3K9 levels were prominent in PCa, and HP1 $\beta$ was overexpressed in highly malignant-potential PCa. HP1 $\beta$ knockdown inhibited cell growth in LNCaP cells that normally express high levels of AR. Furthermore, HP1 $\beta$ expression and meH3K9 levels were up-regulated in castration-resistant $\mathrm{CxR}$ cells compared with the parental LNCaP cells. In addition, HP1 $\beta$ knockdown suppressed the cell growth of CRPC cells more effectively compared with that of parental cells. This study presented a new insight in association among epigenetic regulation, gene expression by $\mathrm{AR}$ and $\mathrm{PCa}$ carcinogenesis and progression. These findings suggest that modulation of HP1 $\beta$ expression or function might be a useful strategy for developing novel therapeutics for PCa, which is usually dependent on androgen/AR signaling. Furthermore, this strategy might be more useful for CRPC, which is more dependent on androgen/AR signaling by overexpressing its coactivators or by histone modification than androgen-dependent $\mathrm{PCa}$. On the other hands, preventing or decreasing methylation of histone $\mathrm{H} 3$ lysine 9 might prevent $\mathrm{PCa}$ carcinogenesis.

\section{Declaration of interest}

The authors declare that there is no conflict of interest that could be perceived as prejudicing the impartiality of the research reported.

\section{Funding}

This work was supported in part by Health Sciences Research Grants for Clinical Research for Evidenced Based Medicine and Grants-in-Aid for Cancer Research (016), from the Ministry of Health, Labor and Welfare, Japan, Young Researcher Promotion Grant from Japanese Urological Association, Japan, Research Promotion Grant from The Japanese Foundation for Prostate Research, Japan and Research Promotion Grant from The Tokyo Biochemical Research Foundation, Japan. 


\section{Acknowledgements}

We are grateful to Dr Toshihiko Yanase (AR-GFP), Dr Chawnshang Chang (pCMV-AR and MMTV-Luc), and Dr Atsushi Mizokami (pGLPSAp5.8) for kindly providing the plasmids in parentheses. We would like to thank Dr Dongchon Kang (Kyushu University, Fukuoka, Japan) for helping with quantitative real-time PCR and flow cytometry, Edanz Group Japan for editorial assistance, and Noriko Hakoda and Seiko Kamori for their technical assistance. The authors would like to acknowledge the technical expertise of the Support Center for Education and Research, Kyushu University.

\section{References}

Cheutin T, McNairn AJ, Jenuwein T, Gilbert DM, Singh PB \& Misteli T 2003 Maintenance of stable heterochromatin domains by dynamic HP1 binding. Science 299 721-725.

Cryderman DE, Tang H, Bell C, Gilmour DS \& Wallrath LL 1999 Heterochromatic silencing of Drosophila heat shock genes acts at the level of promoter potentiation. Nucleic Acids Research 27 3364-3370.

Debes JD \& Tindall DJ 2002 The role of androgens and the androgen receptor in prostate cancer. Cancer Letters 187 1-7.

Dialynas GK, Terjung S, Brown JP, Aucott RL, Baron-Luhr B, Singh PB \& Georgatos SD 2007 Plasticity of HP1 proteins in mammalian cells. Journal of Cell Science 120 3415-3424.

Eissenberg JC \& Elgin SC 2000 The HP1 protein family: getting a grip on chromatin. Current Opinion in Genetics \& Development 10 204-210.

Fanti L \& Pimpinelli S 2008 HP1: a functionally multifaceted protein. Current Opinion in Genetics \& Development 18 169-174.

Feldman BJ \& Feldman D 2001 The development of androgen-independent prostate cancer. Nature Reviews. Cancer $134-45$.

Fujimoto N, Yeh S, Kang HY, Inui S, Chang HC, Mizokami A \& Chang C 1999 Cloning and characterization of androgen receptor coactivator, ARA55, in human prostate. Journal of Biological Chemistry 274 8316-8321.

Gronberg H 2003 Prostate cancer epidemiology. Lancet 361 859-864.

Han M, Partin AW, Piantadosi S, Epstein JI \& Walsh PC 2001 Era specific biochemical recurrence-free survival following radical prostatectomy for clinically localized prostate cancer. Journal of Urology 186 416-419.

Hediger F \& Gasser SM 2006 Heterochromatin protein 1, don't judge the book by its cover!. Current Opinion in Genetics and Development 16 143-150.

Hsing AW \& Devesa SS 2001 Trends and patterns of prostate cancer: what do they suggest? Epidemiologic Reviews $\mathbf{2 3}$ 3-13.

Isaacs W, De Marzo A \& Nelson WG 2002 Focus on prostate cancer. Cancer Cell 2 113-116.
Kang HB, Choi Y, Lee JM, Choi KC, Kim HC, Yoo JY, Lee YH \& Yoon HG 2009 The histone methyltransferase, NSD2, enhances androgen receptor-mediated transcription. FEBS Letters 583 1880-1886.

Liu LP, Ni JQ, Shi YD, Oakeley EJ \& Sun FL 2005 Sex-specific role of Drosophila melanogaster HP1 in regulating chromatin structure and gene transcription. Nature Genetics 37 1361-1366.

Lorentz A, Ostermann K, Fleck O \& Schmidt H 1994 Switching gene swi6, involved in repression of silent mating-type loci in fission yeast, encodes a homologue of chromatin-associated proteins from Drosophila and mammals. Gene 143 139-143.

Lukasova E, Koristek Z, Falk S, Kozubek S, Grigoryev S, Kozubek M, Ondrej V \& Kroupova I 2005 Methylation of histones in myeloid leukemias as a potential marker of granulocyte abnormalities. Journal of Leukocyte Biology 77 100-111.

Miyamoto H, Rahman M, Takatera H, Kang HY, Yeh S, Chang HC, Nishimura K, Fujimoto N \& Chang C 2002 A dominant-negative mutant of androgen receptor coregulator ARA54 inhibits androgen receptor-mediated prostate cancer growth. Journal of Biological Chemistry 277 4609-4617.

Nielsen AL, Ortiz JA, You J, Oulad-Abdelghani M, Khechumian R, Gansmuller A, Chambon P \& Losson R 1999 Interaction with members of the heterochromatin protein 1 (HP1) family and histone deacetylation are differentially involved in transcriptional silencing by members of the TIF1 family. EMBO Journal 18 6385-6395.

Nielsen SJ, Schneider R, Bauer UM, Bannister AJ, Morrison A, O'Carroll D, Firestein R, Cleary M, Jenuwein T, Herrera RE et al. $2001 \mathrm{Rb}$ targets histone H3 methylation and HP1 to promoters. Nature $\mathbf{4 1 2}$ 561-565.

Noma K, Allis CD \& Grewal SI 2001 Transitions in distinct histone $\mathrm{H} 3$ methylation patterns at the heterochromatin domain boundaries. Science 293 1150-1155.

Park SY, Yu X, Ip C, Mohler JL, Bogner PN \& Park YM 2007 Peroxiredoxin 1 interacts with androgen receptor and enhances its transactivation. Cancer Research 67 9294-9303.

Peters AH, O'Carroll D, Scherthan H, Mechtler K, Sauer S, Schofer C, Weipoltshammer K, Pagani M, Lachner M, Kohlmaier A et al. 2001 Loss of the Suv39h histone methyltransferases impairs mammalian heterochromatin and genome stability. Cell 107 323-337.

Piacentini L, Fanti L, Berloco M, Perrini B \& Pimpinelli S 2003 Heterochromatin protein 1 (HP1) is associated with induced gene expression in Drosophila euchromatin. Journal of Cell Biology 161 707-714.

Pomeroy SL, Tamayo P, Gaasenbeek M, Sturla LM, Angelo M, McLaughlin ME, Kim JY, Goumnerova LC, Black PM, Lau C et al. 2002 Prediction of central nervous system embryonal tumour outcome based on gene expression. Nature 415 436-442. 
Shang Y, Myers M \& Brown M 2002 Formation of the androgen receptor transcription complex. Molecular Cell 9 601-610.

Sharma GG, Hwang KK, Pandita RK, Gupta A, Dhar S, Parenteau J, Agarwal M, Worman HJ, Wellinger RJ \& Pandita TK 2003 Human heterochromatin protein 1 isoforms $\mathrm{HP} 1^{\mathrm{Hs} \alpha}$ and $\mathrm{HP} 1^{\mathrm{Hs} \beta}$ interfere with hTERT-telomere interactions and correlate with changes in cell growth and response to ionizing radiation. Molecular and Cellular Biology 23 8363-8376.

Shiota M, Yokomizo A, Tada Y, Inokuchi J, Kashiwagi E, Masubuchi D, Eto M, Uchiumi T \& Naito S 2010 a Castration resistance of prostate cancer cells caused by castration-induced oxidative stress through Twist 1 and androgen receptor overexpression. Oncogene 29 237-250.

Shiota M, Yokomizo A, Tada Y, Inokuchi J, Tatsugami K, Kuroiwa K, Uchiumi T, Fujimoto N, Seki N \& Naito S $2010 b$ Peroxisome proliferator activated receptor $\gamma$ coactivator- $1 \alpha$ interacts with the androgen receptor and promotes prostate cancer cell growth by activating the androgen receptor. Molecular Endocrinology 24 114-127.

Shiota M, Yokomizo A, Masubuchi D, Tada Y, Inokuchi J, Eto M, Uchiumi T, Fujimoto N \& Naito S 2010c Tip60 promotes prostate cancer cell proliferation by translocation of androgen receptor into the nucleus. Prostate $\mathbf{7 2}$ 97-102.

Spierer A, Seum C, Delattre M \& Spierer P 2005 Loss of the modifiers of variegation $\mathrm{Su}(\mathrm{var}) 3-7$ or HP1 impacts male $\mathrm{X}$ polytene chromosome morphology and dosage compensation. Journal of Cell Science 118 5047-5057.
Wang G, Ma A, Chow CM, Horsley D, Brown NR, Cowell IG \& Singh PB 2000 Conservation of heterochromatin protein 1 function. Molecular and Cellular Biology 20 6970-6983.

Wang Q, Li W, Zhang Y, Yuan X, Xu K, Yu J, Chen Z, Beroukhim R, Wang H, Lupien M et al. 2009 Androgen receptor regulates a distinct transcriptional program in androgen-independent prostate cancer. Cell $\mathbf{1 3 8}$ 245-256.

Wasenius VM, Hemmer S, Kettunen E, Knuutila S, Franssila K \& Joensuu H 2003 Hepatocyte growth factor receptor, matrix metalloproteinase-11, tissue inhibitor of metalloproteinase-1, and fibronectin are up-regulated in papillary thyroid carcinoma: a cDNA and tissue microarray study. Clinical Cancer Research 9 $68-75$.

de Wit E, Greil F \& van Steensel B 2007 High-resolution mapping reveals links of HP1 with active and inactive chromatin components. PLoS Genetics 3 e38.

Yahi H, Fritsch L, Philipot O, Guasconi V, Souidi M, Robin P, Polesskaya A, Losson R, Harel-Bellan A \& Ait-Si-Ali S 2008 Differential cooperation between heterochromatin protein HP1 isoforms and MyoD in myoblasts. Journal of Biological Chemistry 283 23692-23700.

Zhao T, Heyduk T, Allis CD \& Eissenberg JC 2000 Heterochromatin protein 1 binds to nucleosomes and DNA in vitro. Journal of Biological Chemistry 275 28332-28338.

Zoubeidi A, Zardan A, Beraldi E, Fazli L, Sowery R, Rennie P, Nelson C \& Gleave M 2007 Cooperative interaction between androgen receptor (AR) and heat-shock protein 27 facilitate AR transcriptional activity. Cancer Research 67 10455-10465. 